\title{
Effects of activated carbon on the growth of Chlorella vulgaris in an aqueous solution
}

\section{Emily Agar, Jordyn Divok, Alannah Penno}

Department of Integrative Biology, University of Guelph, Guelph, ON Canada. Faculty supervisors: Karl Cottenie and Andrew MacDougall. For correspondence, please email: agar.emily@gmail.com; jordydivok@sympatico.ca; azpenno@gmail.com

\section{Abstract}

Algal blooms, if left unmanaged, can negatively impact lake ecosystems. An unexplored method of removing excess nutrients from lakes, and therefore reducing algal blooms, is through the use of biochar. We hypothesize that due to the adsorptive characteristics of pyrolyzed material such as biochar and activated carbon, its presence would reduce the nutrient availability within aqueous solutions, therefore reducing algal growth. This experiment was conducted in an aqueous solution containing СОМВO growth medium with and without the presence of activated carbon, studied under four conditions: $5 \mathrm{mg} / \mathrm{L}, 10 \mathrm{mg} / \mathrm{L}, 20 \mathrm{mg} / \mathrm{L}$, and $50 \mathrm{mg} / \mathrm{L}$ phosphorous. We measured the fluorescence of the samples over a 12 day period to quantify algal growth. An analysis of covariance followed by a Tukey's HSD test demonstrated a significant difference between the mean amount and rate of algal growth in samples containing activated carbon, compared to samples without, with samples containing activated carbon showing less growth $(p<0.0001)$. Further, the concentration of both phosphorus and nitrogen in samples containing activated carbon were lower than in samples without, though these results were inconclusive. Our study demonstrates that activated carbon has the capacity to be used to reduce algal growth, likely due to its capacity to adsorb nutrients such as phosphorous and nitrogen. This suggests that both activated carbon, as well as its more adsorptive counterpart, biochar, have the potential to be used in mitigating algal blooms and, more importantly, reducing the effects of anthropogenic eutrophication in aqueous environments.

Keywords: Biochar; activated carbon; eutrophication; phosphorous adsorption

\section{Introduction}

Algal blooms, if left unmanaged, can have serious negative impacts on lake ecosystems (Conley et al. 2009; Michalak et al. 2012). Anthropogenic pollution has led to an increase in the amounts of phosphorous and nitrogen entering waterways, encouraging the growth of algal blooms, with phosphorous acting as the main limiting nutrient for algal growth (Conley et al. 2009; Paerl 2009; Lewis 2011). Algae, such as Chlorella vulgaris, flourish in nutrient-rich environments, resulting in an increase in their abundance (Paerl 2009). Increases in algal abundance within lakes reduces the amount of light that reaches the lake bed, resulting in benthic species being unable to photosynthesize, creating an anoxic environment and reducing lake biodiversity (Hautier et al. 2009; Ansari \& Singh Gill 2014).

Evidence of eutrophication has been apparent in the Great Lakes from the 1960s (Scavia et al 2014). The Great Lakes Water Quality Agreement of 1972 has helped manage one of the main causes of eutrophication: rising levels of phosphorous (Hartig et al. 1990). The management initiative's objective was to control algal blooms in the lower lakes and to maintain the oligotrophic conditions of the upper lakes (Hartig et al. 1990). Despite management initiatives, eutrophication in the Great Lakes has increased since 1990 (Scavia et al. 2014). This eutrophication has created hypoxic conditions which threatens macroinvertebrates, many of which are benthic prey species that are important food sources for higher trophic levels (Scavia et al. 2014). These conditions reduce the water quality, effectively eliminating the conditions that are vital to the macroinvertebrates and the biodiversity found within the Great Lakes cold-water habitat (Scavia et al. 2014). Local communities and government stakeholders are investigating means of reducing eutrophication and returning nutrient concentrations to moderate levels (Schindler and Vallentyne 2008; Ruiz et al. 2011; Michalak et al. 2012). Doing so would prevent algal growth from reaching adverse levels, maintaining biodiverse communities within the aquatic ecosystem and improving the water quality upon which many non-aquatic species rely (Ansari and Singh Gill 2009).

An unexplored method of removing excess nutrients from lakes is through the use of biochar. Biochar is a substance created from biomass that has been pyrolyzed 
under anaerobic conditions (Brown 2009). It is most commonly used as a soil additive for increasing plant growth and soil quality, which it does by enriching soils through its adsorptive capabilities, ultimately reducing nutrient leaching (Warnock et al. 2007). Its ability to adsorb pollutants in soil has also proven effective for removing pollutants from agricultural farm runoff (Beck et al. 2011; Knowles et al. 2011). Biochar has also shown promise as a means of reducing chemical contamination, particularly as a treatment for wastewater (Kimetu et al. 2014).

While several studies have investigated the potential uses of biochar as a method of filtering wastewater and for use in soil (Chen et al. 2011; Dalahmeh et al. 2012; Fang et al. 2014), very little of the research considers the potential environmental effects of the application of biochar to aquatic environments (Morales et al. 2013; Chintala et al. 2014; Soinne et al. 2014; Xu et al. 2014). Of the studies previously conducted, the use of biochar within wastewater filtration systems demonstrates that biochar has the capacity to adsorb phosphorous and nitrogen (Chen et al. 2011; Dalahmeh et al. 2012; Fang et al. 2014). These studies focus on the use of biochar in the filtration of human wastewater, which benefits humanity by developing and improving wastewater treatment practices (Chen et al. 2011; Dalahmeh et al. 2012; Fang et al. 2014). However, throughout the current scientific literature, there is a lack of focus on the use of biochar as a filtration system within the natural environment.

This raises the question of how biochar and its nutrient adsorbing qualities could be used within natural water systems, in particular, if it could affect the growth of algae through interactions with aqueous phosphorous. Previous studies suggest that biochar is able to adsorb both nitrogen and phosphorous (Beck et al. 2011; Berger 2012), but because phosphorous is usually the limiting agent for algal growth, we will focus our study upon this nutrient. Our research study aims to address how biochar could be used within aquatic environments to reduce algal growth. Biochar has been shown to have a greater adsorptive capacity than other pyrolyzed material, such as activated carbon, and is also less costly and labour intensive to make (Huggins et al. 2016). Despite these superior qualities, biochar is not easily accessible for use due to its novelty and the need for ongoing research on its chemical properties and potential applications (Berger 2012; Kimetu et al. 2016). Due to the lack of knowledge and availability of biochar, activated carbon has been substituted for biochar in our experiment as it has similar, though less effective, adsorptive characteristics.

Based on activated carbon's capacity to adsorb phosphorous, we hypothesized that the growth of algae would be impeded by the addition of activated carbon. Thus, solution samples without the addition of activated carbon will contain higher levels of phosphorous compared to samples which have had activated carbon added.

\section{Methods and Materials}

To test our hypothesis, we manipulated levels of phosphorous and the presence of activated carbon in a diluted algal growth medium to observe their effects on algal growth. The single-celled green algae, Chlorella vulgaris, was used in this study due to its growth being dependent upon the presence of phosphorous (Ruiz et al. 2011). C. vulgaris was also chosen due to the ease with which changes in population abundance can be observed through its ability to fluoresce, with higher fluorescence readings corresponding with larger populations (Tang et al. 2016). Fluorescence measurements were used to determine algal growth over time, with data readings collected at $405 \mu \mathrm{m}$. To observe potential relationships of algal growth to nutrient availability, we also recorded phosphorous and nitrogen readings using API aquarium nutrient tests. Phosphorous and nitrogen readings were taken on the first day of the experiment to give baseline readings of the nutrient concentrations in each treatment, and as well as on the fourth and last days of the experiment (Aquarium Pharmaceutical Incorporated: Nebraska, U.S.). The API tests involved taking a $5 \mathrm{~mL}$ measure from each sample and adding drops of the respective phosphate and nitrogen test solutions to these measures. The resulting colour change of the $5 \mathrm{~mL}$ measure and test solution mixture was then compared against a chart of colours included with the tests, which indicated the concentrations of phosphorous or nitrogen within that sample.

Forty 1-L beakers were used, into which $2 \mathrm{~mL}$ of $C$. vulgaris inoculant, $500 \mathrm{~mL}$ of diluted algal growth medium, and $12.5 \mathrm{mg}$ of nitrogen $(25 \mathrm{mg} / \mathrm{L})$ were added. Before being added, the inoculant was agitated by stirring to ensure an equal amount of algal cells would be present in each addition. This nitrogen concentration was chosen and added to all treatments to ensure that nitrogen would not act as the limiting growth factor, as $25 \mathrm{mg} / \mathrm{L}$ is well above the threshold required for algal blooms to form (Paerl, 2009; The 2012 Canada-US Great Lakes Water Quality Agreement, Annex 4). The COMBO algal growth medium was diluted to a concentration of $10 \%$ with distilled water to ensure minimum nutrient levels were established (Kilham et al., 1998). The phosphorous values were chosen to be above the threshold at which algal blooms are known to occur, $5 \mu \mathrm{g} / \mathrm{L}$ (Paerl, 2009; The 2012 Canada-US Great Lakes Water Quality Agreement, Annex 4). Based upon this average, we set up four experimental concentrations of added phosphorous $(0 \mathrm{mg} / \mathrm{L}, 5 \mathrm{mg} / \mathrm{L}, 20 \mathrm{mg} / \mathrm{L}, 50 \mathrm{mg} / \mathrm{L})$. Ten beakers per each concentration treatment were created, with 
each set of ten being further subdivided into five beakers of each treatment containing AquaClear aquarium filter activated carbon and five without.

The amount of activated carbon used in this experiment was modified from a study conducted by Beck et al. (2011), which used a ratio of $7 \%$ by mass of biochar to volume of the rainwater runoff solution in litres. We replicated this ratio based on our experimental volumes, and then further reduced the amount of activated carbon due to the size restriction of the tea bags used to hold the activated carbon. Tea bags were used to prevent the solutions from being clouded by particles of the activated carbon, which would interfere with the fluorometer readings. Empty tea bags were added to the treatments without the activated carbon to standardize all treatments and reduce the presence of confounding variables. The beakers were kept under wide-spectrum LED lights, which provided photosynthetic active radiation at wavelengths $400 \mathrm{~nm}$ to $700 \mathrm{~nm}$, to encourage algal growth, and were covered with plastic film to reduce the loss of solution through evaporation and to prevent contamination. Each solution was stirred uniformly each day before the fluorometer readings were taken, to ensure that the algae remained suspended and did not develop uneven growth within the samples.

A fluorescence spectrophotometer, at wavelength 405 $\mathrm{nm}$, was used to compare algal growth every day for two weeks, from October 17th to 31st. Data was lost from October 17th to 19th as well as October 30th due to equipment failure, and so the data analysis compares data collected from October 20th to October 31st, excluding October 30th; therefore, day 1 to 12 , excluding day 11 . The equipment failure was due to incorrect calibration by previous users of the spectrophotometer, and was resolved for our further use.

Using the replications of our data for the treatment variables, JMP software (SAS Institute Inc. 2017) was used to conduct the statistical analyses on the data. The independent variables - presence of activated carbon, $\mathrm{P}$ concentration, and day - were compared and contrasted using an analysis of covariance (ANCOVA) to determine their individual and combined effects on the fluorescence readings for each treatment. Due to its conservative nature (Steinberg 2011), the Tukey's HSD test was used as a post-hoc test following the ANCOVA, which excluded data collected the 11 th day of our experiment due to equipment failure. An $\alpha-$ value of 0.05 was used to determine significance in these analyses. Treatments with a phosphorous level of $50 \mathrm{mg} / \mathrm{L}$ was also excluded after an initial analysis (Table 1) which demonstrated an obvious divergence in this data from the trend of the other treatment types. We believe this may have resulted due to the phosphorus concentration reaching a high enough level that the algal carrying capacity was reached at a faster rate than the other samples, therefore levelling off sooner than the other samples, though this needs to be confirmed through further experimentation.

\section{Results}

With the exclusion of day 11 data and data for the treatment containing $50 \mathrm{mg} / \mathrm{L}$ of phosphorous, the results of the ANCOVA for fluorometer readings were significant for all variables - time (day), presence of activated carbon, and treatment type - and their combinations $(p<0.0001$; Figure 1, Table 1). There was a visibly noticeable difference in the amount of algal growth between treatments with the presence versus absence of activated carbon during early readings in the experiment (Figure 2), though this difference decreased towards the end of data collection (Figure 2). The Tukey's HSD test demonstrated a significant difference between the means of samples containing activated carbon compared to samples without; samples with activated carbon had a lower mean than those without in each treatment type, supporting our hypothesis $(\mathrm{p}<0.05$; Table 3$)$.

Additional ANCOVA analyses were performed for the phosphorous and nitrogen readings. When analyzing all treatments with and without activated carbon, most variables had a significant effect on nitrogen readings, in which samples with activated carbon had lower nitrogen levels than those without $(p<0.05)$ (Figure 3). Exceptions to this were the combined effects of "activated carbon*treatment type" and "time*activated carbon*treatment type" (Figure 3, Table 4). Similarly, most variables had a significant effect on phosphorous readings $(p<0.05)$ with the exception of combined effects for "time*activated carbon" and "treatment type*activated carbon" ( $p=0.6037$ and $p=0.2344$ respectively; Figure 3, Table 5). Phosphorous readings were significantly different between samples with and without activated carbon for the conditions of $0 \mathrm{mg} / \mathrm{L}$ treatment with effect of "day" ( $p=0.0279), 20 \mathrm{mg} / \mathrm{L}$ treatment with effect of "day" ( $p=0.0001)$, and $50 \mathrm{mg} / \mathrm{L}$ treatment with effect of "day" $(\mathrm{p}=0.0295)$.

\section{Discussion}

Our hypothesis that the growth of algal blooms will be impeded by the addition of activated carbon was supported by our findings. The addition of activated carbon reduces the growth of $C$. vulgaris through, as we have interpreted from our results, the reduction of available nutrients, notably phosphorous and nitrogen (Dempster et al. 2012; Tang et al. 2016). Based upon the experiment's findings and the findings in the current scientific literature, it is evident that biochar would likely be capable of reducing levels of 
nitrogen and phosphorous in aqueous solutions (Beck et al. 2011; Supplementary Table 2, Supplementary Table 3). The algal growth rates differed between treatments with and without activated carbon, with the algae growing at a slower rate in treatments containing activated carbon (Figure 2). This follows our hypothesis, that algal growth would be limited by the presence of activated carbon.

The phosphorous and nitrogen readings, excluding irregular results due to equipment failure, showed that the presence of activated carbon impacted the levels of these nutrients, though individual treatment analyses were not statistically significant for all variables. Firstly, while the level of nitrogen unexpectedly increased over the course of the experiment, treatments with activated carbon contained lower levels of nitrogen than those without (Figure 3). While it appears that the nitrogen levels increased, it is possible that the presence of algae skewed the results of the nitrogen tests. Algae, whose dry mass has been shown to be composed of $10 \%$ nitrogen (Ferrera-Lorenzo et al. 2013), releases nitrogen as it decomposes, and so may have resulted in an increase in the recorded nitrogen levels as algal cells began to die off. Through preventing the growth of algae, the presence of activated carbon indirectly resulted in a lower level of nitrogen due to the reduced amount of algae available for decomposition when compared to solutions without its presence. More studies should be conducted to further confirm this effect. This is observable in Figure 3, which demonstrates a lower increase in nitrogen levels in treatments containing activated carbon compared to those without. Further, the ANCOVA shows that all data for the effects of variables and their combinations on the nitrogen readings were significant $(\mathrm{p}<0.05)$ when all treatment types were considered, excluding the combined effects of "activated carbon*treatment type" and "time*activated carbon*treatment type" (Table 4). Interestingly, significance was not found when considering each treatment type individually and the effects of variables "activated carbon*day", "activated carbon", and "day" (Supplementary Figure 1).

Secondly, the phosphorus readings were also influenced by the presence of activated carbon. Though the phosphorous readings decreased in solutions with and without activated carbon - excluding treatments $0 \mathrm{mg} / \mathrm{L}$ with and without activated carbon and $5 \mathrm{mg} / \mathrm{L}$ with activated carbon - the solutions with activated carbon had a greater decrease than those without (Supplementary Figure 2). The ANCOVA shows all data for the effects of variables and their combinations on the phosphorous readings were significant ( $p<0.05)$, except for the combined effects of "time*activated carbon" and "activated carbon*treatment type" (Table 4). Interestingly, when the treatment types were analyzed in isolation, only the "day" variable was significant for treatment type $0 \mathrm{mg} / \mathrm{L}, 20 \mathrm{mg} / \mathrm{L}$, and $50 \mathrm{mg} / \mathrm{L}$ (Supplementary Figure 2).

The nitrogen and phosphorous tests compared the solution to a chemical indicator colour chart by eye, and so human error along with algal colour interference may account for these results, particularly the inclining slopes of best fit for nitrogen readings (Figure 3). The colour of the solutions was affected by the presence of the algae, which gave the solutions a light green hue. Human error may have occurred due to the solutions being similar in colour to the phosphorous colour chart, which used shades of blue and green, potentially skewing the results towards higher phosphorous levels. The API nutrient tests are intended to be used to roughly estimate nutrient levels in home aquariums, and so while they provided a valuable dimension to our experiment, the results we gathered using them should be taken with some scepticism. Using more sophisticated equipment for measuring nitrogen and phosphorous would provide a better gradient of nutrient levels over the course of the experiment, and therefore more accurate measurements of adsorption by the activated carbon. Further, when performing analyses for each treatment individually, five replicates per treatment may have been too small a sample size to accurately show potential changes in phosphorous or nitrogen quantities within the samples. Future studies should use larger sample sizes along with more sensitive nutrient level reading equipment to determine if these results are accurate, or if they may have been due to other factors such as human error. More studies should be conducted to further confirm the adsorptive effects of activated carbon on nitrogen and phosphorous.

Recent studies suggest that rather than reductions of phosphorous alone, simultaneous reductions of both nitrogen and phosphorous are more successful at reducing anthropogenic eutrophication within inland lakes (Conley et al. 2009; Paerl 2009; Lewis 2011). Phosphorous is the largest limiting factor of algal blooms, however if phosphorous concentrations are low, nitrogen can become the limiting agent (Conley et al. 2009; Paerl 2009). Procedures have been implemented to reduce phosphorous levels in hypereutrophic lakes, such as reducing water runoff from agricultural practices and treating wastewater prior to discharge (Schindler and Vallentyne 2008). Unfortunately, these proactive measures do not effectively reduce the impacts of nitrogen and phosphorous already present in lakes (Liu and Qui 2007). Developing novel, more efficient methods of removing excess phosphorous and nitrogen can benefit the conservation and rehabilitation of lake ecosystems. Our study demonstrates that activated carbon has the capacity to be used for the adsorption of phosphorous, presenting positive implications for the use of biochar to remedy anthropogenic eutrophication. 
Biochar is similar to activated carbon, but has been shown to be more effective at adsorbing nutrients in both soil and aqueous solutions (Berger 2012; Morales et al. 2013; Huggins et al. 2016). This suggests that biochar could be more effective than activated carbon for reducing levels of anthropogenic nutrients in inland lakes, and therefore, a better management tool for conserving lake ecosystems. From our findings, we can speculate that biochar would be more effective at adsorbing phosphorous than activated carbon, and so future studies should focus on investigating the potential for biochar to reduce the growth of algae. Future studies should also conduct the study for a longer period to ensure the algae populations within each sample condition reaches its maximum abundance. Our graph readings of fluorescence did not reach asymptotic conditions, which is indicative of an organism reaching carrying capacity (Parkhurst 2006). This would enable a comparison not only of the rate of algal growth occurring as a result of the addition of biochar, but also the maximum abundance in each condition as well.

Alternative methods could be used in future studies, including the use of different algae species and treatment conditions. For instance, the effect of zooplankton on the population densities of algae may aid in understanding the impacts of biochar in a more natural environment. Further studies could consider the use of biochar in natural conditions, such as aquatic basin ecosystems, and how they react to the presence of activated carbon or biochar. The possible impacts that the addition of biochar may have upon an environment, such as changes to substrate carbon levels and levels of waterborne nutrients other than phosphorous and nitrogen, also need to be explored.

In conclusion, our study highlights the adsorptive capabilities of activated carbon, as well as the interactions it has with C. vulgaris algae. This carries implications for the future use of activated carbon, and similarly biochar, as a means of reducing anthropogenic eutrophication and its larger impact on aqueous environments.

\section{Acknowledgements}

Many thanks to Andrew Macdougall and Karl Cottenie, both of whom provided endless wisdom, guidance, and support throughout this process. Thank you to Laura Armstrong, whose help with the initial foundations of this project was essential. A special thank you to Gustavo Betini whose considerable knowledge of algae and their optimal environments ensured that our project ran smoothly, and whose contribution of equipment to this project was greatly appreciated. Our appreciation also goes out to Sheri Hincks for her contribution of COMBO algal growth medium, Linda Varangu for the full spectrum LED grow lights, and Peter
Smith for the fluorometer equipment, all of which was essential to the success of our project.

\section{References}

Ansari AA, Singh Gill S. 2014. Eutrophication: causes, consequences and control, 2. New York, NY: Springer.

Beck DA, Johnson GR, Spolek GA. 2011. Amending greenroof soil with biochar to affect runoff water quantity and quality. Environmental Pollution. 159, 2111-2118.

Berger C. 2012. Biochar and activated carbon filters for greywater treatment - comparison of organic matter and nutrients removal. Swedish University for Agricultural Sciences. [Internet]. [cited 2016 September 29]; n/a, $\mathrm{n} / \mathrm{a}$. Available from: http://stud.epsilon.slu.se/5183/21/berger_c 130115.pdf

BioMerieux $^{\circledR}$, Nitrate test kit. Aquarium Pharmaceuticals Inc., Nebraska, U.S.

BioMerieux $^{\circledR}$, Phosphate test kit. Aquarium Pharmaceuticals Inc., Nebraska, U.S.

Brown R. 2009. Biochar production technology. In: Lehmann J, Joseph S, editors. Biochar for environmental management: science and technology. London, UK: Earthscan.

Chen B, Chen Z, Lv S. 2011. A novel magnetic biochar efficiently sorbs organic pollutants and phosphate. Bioresource Technology. 102: 716 -723.

Chintala R, Schumacher TE, McDonald LM, Clay DE, Malo DD, Papiernik SK, Julson JL. 2014. Phosphorous sorption and availability from biochars and soil/biochar mixtures. Clean-Soil, Air, Water. [Internet]. [cited 2016 October 15]; 42: 626-634. Available from: http://onlinelibrary.wiley.com/doi/10.1002/clen.2013000 89/full doi: 10.1002/clen.201300089

Conley DJ, Paerl HW, Howarth RW, Boesch DF, Seitzinger SP, Havens KE, Likens GE. 2009. Controlling eutrophication: nitrogen and phosphorous. Science. 323: 1014-1015.

Dalahmeh SS, Pell M, Vinnerås B, Hylander LD, Öborn I, Jönsson H. 2012. Efficiency of bark, activated charcoal, foam and sand filters in reducing pollutants from greywater. Water, Air and Soil Pollution. 223: 36573671.

Dempster DN, Jones DL, Murphy DV. 2012. Clay and biochar amendments decreased inorganic but not 
dissolved organic nitrogen leaching in soil. Soil Research. 50: 216-221.

Fang C, Zhang T, Li P, Jiang RF, Wang YC. 2014. Application of magnesium modified corn biochar for phosphorous removal and recovery from swine wastewater. International Journal of Environmental Research and Public Health. [Internet]. [cited 2016 November 12]; 11: 9217-9237. Available from: http://www.mdpi.com/journal/ijerph doi: $\underline{10.3390 / \text { ijerph110909217 }}$

Ferrara-Lorenzo N, Fuente E, Suarez-Ruiz I, Ruiz B. 2013. Pyrolysis characteristics of a macroalgae solid waste generated by the industrial production of Agar-Agar. Journal of Analytical and Applied Pyrolysis. 105: 209216.

Hautier Y, Niklaus PA, Hector A. 2009. Competition for light causes plant biodiversity loss after eutrophication. Science. 324: 636-638.

Huggins TM, Haeger A, Biffinger JC, Ren ZR. 2016. Granular biochar compared with activated carbon for wastewater treatment and resource recovery. Water Research. 94: 225-232.

JMP $^{\circledR}, 10$. SAS Institute Inc., Cary, NC, 1989-2007.

Kilham SS, Kreeger DA, Lynn SG, Goulden CE, Herrera L. 1998. COMBO: A defined freshwater culture medium for algae and zooplankton. Hydrobiologia. 377: 147-159.

Kimetu JM, Hill JM, Husein M, Bergerson J, Layzell DB. 2014. Using activated biochar for greenhouse gas mitigation and industrial water treatment. Mitigation and Adaptation Strategies for Global Change. 21: 761-777.

Knowles OA, Robinson BH, Contangelo A, Clucas L. 2011. Biochar for the mitigation of nitrate leaching from soil amended with biosolids. Science of the Total Environment. 409: 3206-3210.

Lewis Jr. W. 2011. Rationale for control of anthropogenic nitrogen and phosphorous to reduce eutrophication of inland waters. Environmental Science and Technology. 45: 10300-10305.

Michalak AM, Anderson EJ, Beletsky D, Boland S, Bosch NS, Bridgeman TB, Zagorski MA. 2012. Record-setting algal bloom in Lake Erie caused by agricultural and meteorological trends consistent with expected future conditions. Proceedings of the National Academy of Sciences of the United States of America. 110: 64486452.
Morales MM, Comerford N, Guerrini IA, Falcão NPS, Reeves JB. 2013. Sorption and desorption of phosphate on biochar and biochar-soil mixtures. Soil Use and Management. 29: 306-314.

Paerl H. 2009. Controlling eutrophication along the freshwater-marine continuum: dual nutrient ( $\mathrm{N}$ and $\mathrm{P}$ ) reductions are essential. Estuaries and Coasts. 32: 593601 .

Parkhurst DF. 2006. Introduction to applied mathematics for environmental science. New York, New York: Springer. $122 \mathrm{p}$.

Ruiz J, Alvarez P, Arbib Z, Garrido C, Barragan J, Perales JA. 2011. Effect of nitrogen and phosphorous concentration on their removal kinetic in treated urban wastewater by Chlorella vulgaris. International Journal of Phytoremediation. 13: 884-896.

Schindler DW, Vallentyne JR. 2008. The algal bowl: Overfertilization of the World's Freshwaters and Estuaries. Edmonton, AB: University of Alberta Press. $334 \mathrm{p}$.

Soinne H, Hovi J, Tammeorg P, Turtola E. 2014. Effect of biochar on phosphorous sorption and clay soil aggregate stability. Geoderma. 219-220: 162-167.

Steinberg WJ. 2011. Statistics Alive! 2nd Ed. Thousand Oaks, California: Sage Publications Inc. 597 p.

Tang C, Li Y, Acharya K. 2016. Modeling the effects of external nutrient reductions on algal blooms in hypereutrophic Lake Taihu, China. Ecological Engineering. 94: 164-173.

The 2012 Canada-US Great Lakes Water Quality Agreement, 2012. Can.-U.S., Annex 4.

Warnock DD, Lehmann J, Kuyper TW, Rillig MC. 2007. Mycorrhizal responses to biochar in soil - concepts and mechanisms. Plant and Soil. 300: 9-20.

Xu G, Sun J, Shao H, Chang SX. 2014. Biochar had effects on phosphorous sorption and desorption in three soils with differing acidity. Ecological Engineering. 62: 54 60 . 


\section{Figures and Tables}

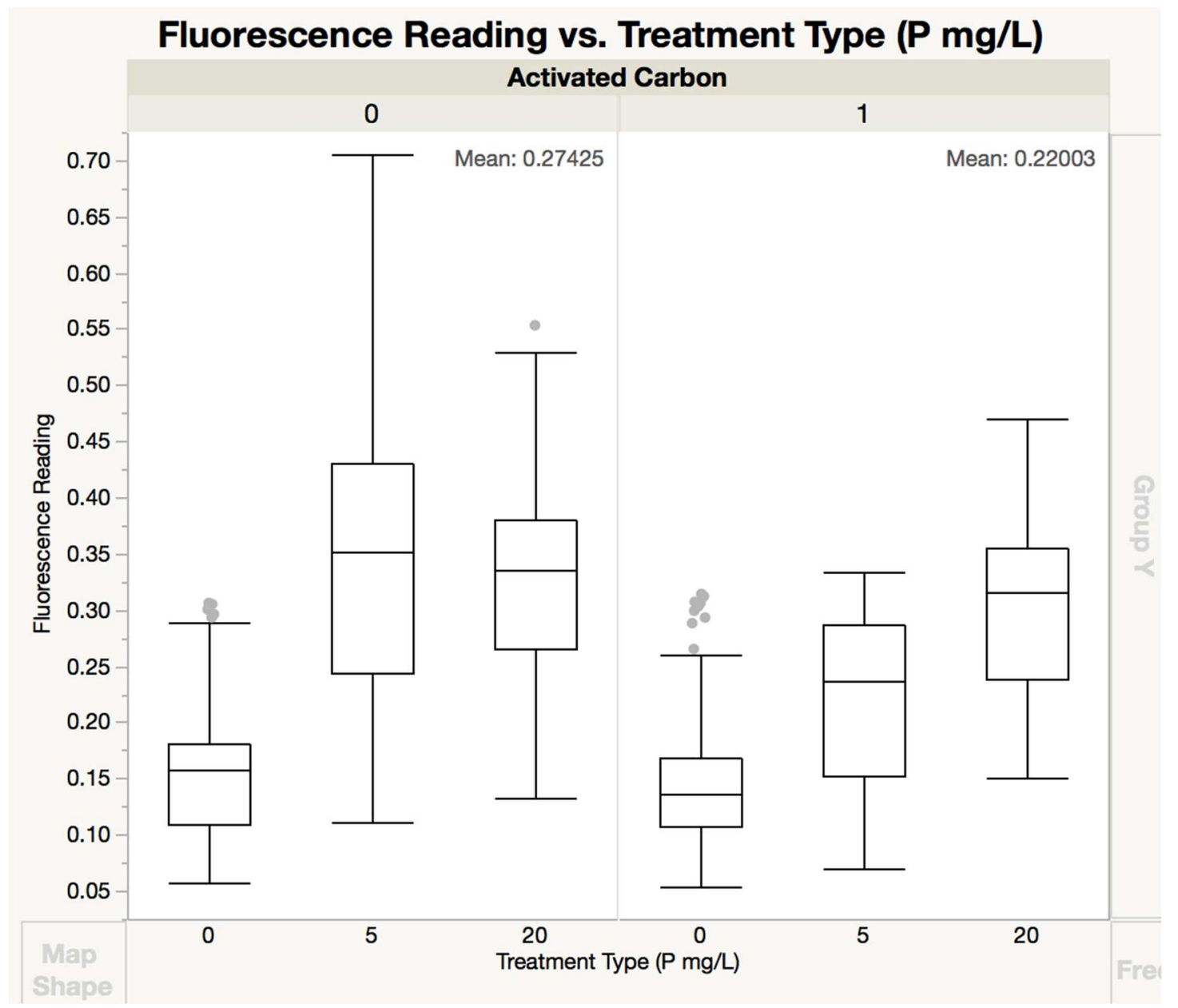

Figure 1. Boxplots Displaying Differences in Algae Fluorescence Readings. Boxplots of fluorescence values demonstrate algal concentrations over time in the solutions, with the initial algal concentration having been standardized at the beginning of the experiment. This figure demonstrates the correlation between fluorescence readings and the treatment type (phosphorous $\mathrm{mg} / \mathrm{L}$ ) and presence of activated carbon. The absence of activated carbon is denoted by a 0 , while the presence of activated carbon is denoted by 1 . The graph excludes data collected on October 30th, and data collected from treatments containing $50 \mathrm{mg} / \mathrm{L}$ of phosphorous. The figure refers to nitrogen and phosphorous information from table 2 . 

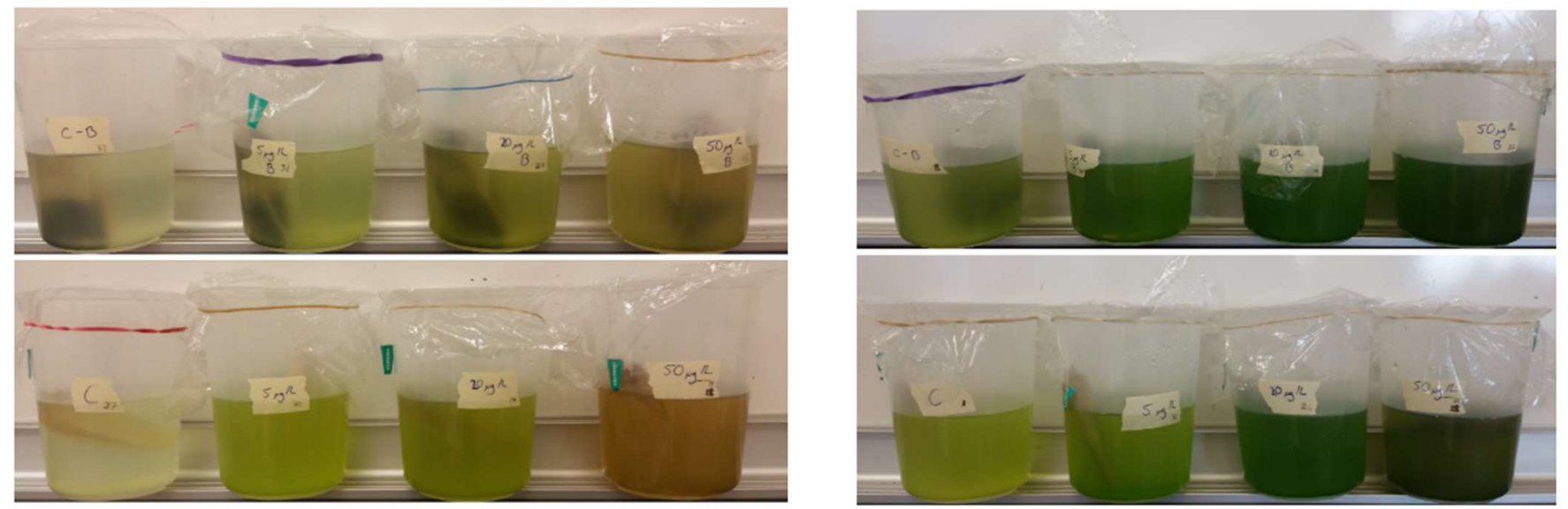

Figure 2. Display of Beakers Showing Colour Differential from October 21st (left) and November 1st (right). Treatments on the top row contain activated carbon, and treatments on the bottom do not. From left to right: treatments containing $0 \mathrm{mg} / \mathrm{L}$ of phosphorous (control), $5 \mathrm{mg} / \mathrm{L}$ of phosphorous, $20 \mathrm{mg} / \mathrm{L}$ of phosphorous, and $50 \mathrm{mg} / \mathrm{L}$ of phosphorous.
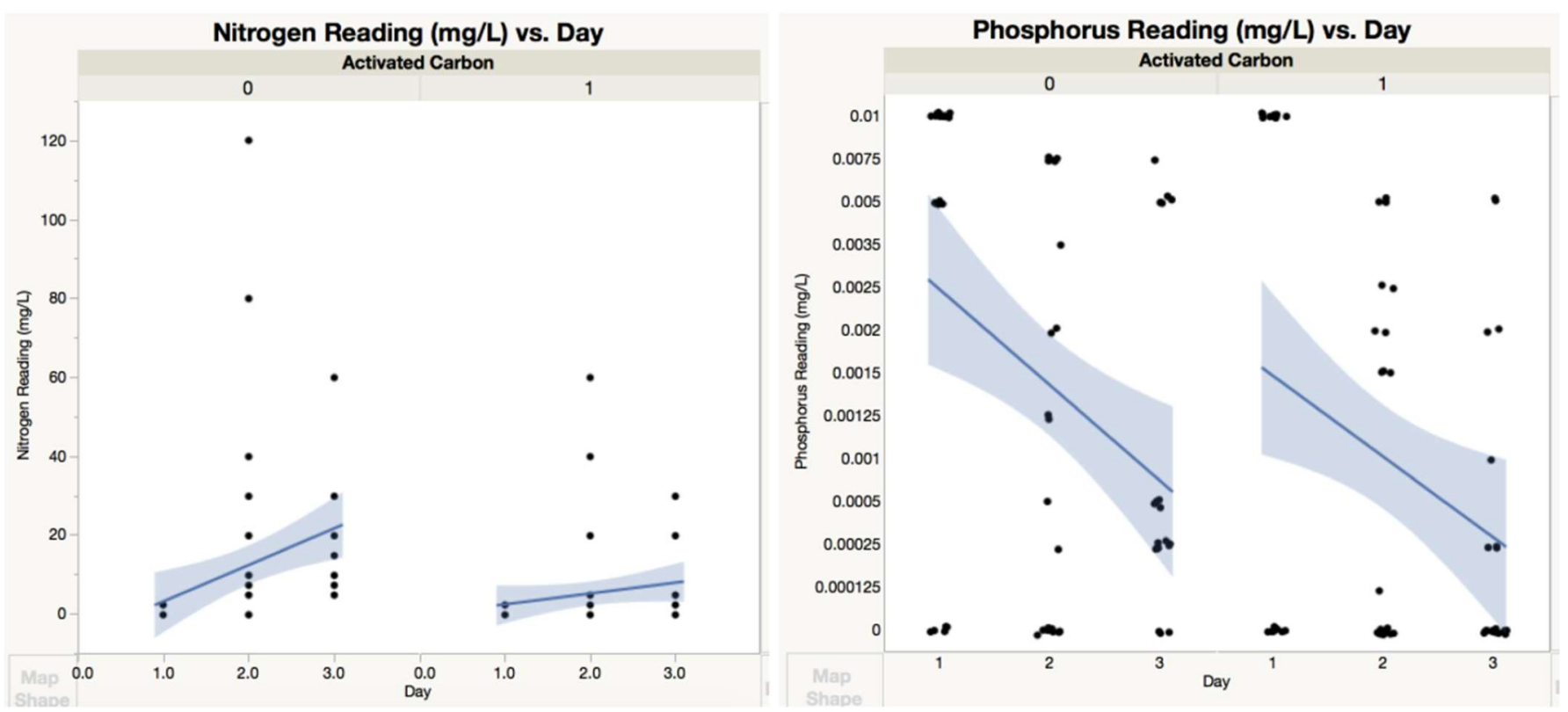

Figure 3. Scatterplots Based on Nitrogen and Phosphorous Values for Treatment Types with and without Activated Carbon. Scatterplots graphing the nitrogen and phosphorous readings over time for both the presence and absence of activated carbon. API Aquarium nitrogen and phosphorus tests nitrogen and phosphorus tests were used to quantify values of these elements in the solutions (Aquarium Pharmaceutical Incorporated: Nebraska, U.S). Lines of best fit traversing the data values provide an estimate of the change in nitrogen and phosphorous readings over the collection period. The figure refers to nitrogen and phosphorous data isolating treatment types, compared to Table 4 and 5 which combine all treatment types with the analyses. Results conveyed by the scatterplots are expanded upon within the supplementary information. 
Table 1. ANCOVA Summary Table of Fluorescence Values. The table references data presented in Figure 2. Table outlining significance of main and interactive effects of the treatment conditions, data collection days, and presence or absence of activated carbon on the fluorescence readings. The "** is used to represent interactions between the variables while "DF" denotes the degrees of freedom for each analysis of covariance. The table excludes data collected on October 30th.

\begin{tabular}{|l|c|c|c|c|}
\hline Source & DF & \multicolumn{2}{c|}{ F Ratio } \\
\hline Activated Carbon & 1 & 0.5346632 & 110.398 & $<0.0001^{*}$ \\
\hline Treatment (mg/L) & 1 & 2.4326984 & 502.3068 & $<0.0001^{*}$ \\
\hline Time (Day) & 1 & 4.8050256 & 16.1727 \\
\hline Time*Activated Carbon & 1 & 0.0783251 & 39.8956 & $<0.0001^{*}<0.0001^{*}$ \\
\hline Treatment*Activated Carbon & 1 & 0.1876575 & 18.4419 & $<0.0001 *$ \\
\hline Time*Treatment*Activated Carbon & 1 & 0.0893151 & $<0.0001^{*}$ \\
\hline
\end{tabular}

Table 2. ANCOVA Summary Table of Fluorescence Values, Excluding Those from October 30th and the $50 \mathrm{mg} / \mathrm{L}$ phosphorous-Containing Treatments. The table references data in Figure 2. Table outlining significance of main and interactive effects of the treatment conditions, data collection days, and presence or absence of activated carbon on the fluorescence readings. The "*" is used to represent interactions between the variables while "DF" denotes the degrees of freedom for each analysis of covariance. The graph excludes data collected on October 30 th, and data collected from treatments containing 50 mg/L of phosphorous.

\begin{tabular}{|l|c|c|c|c|}
\hline Source & DF & Sum of Squares & 783.2511 & $<$ Prob $>$ F \\
\hline Activated Carbon & 1 & 0.7276080 & 2706.491 & $<0.0001 *$ \\
\hline Treatment (mg/L) & 1 & 5.0284369 & 6548.781 & 165.4496 \\
\hline Time (Day) & 1 & 6.0835479 & 342.6594 & $<0.0001 *$ \\
\hline Time*Activated Carbon & 1 & 0.1536958 & $<0.0001 *$ \\
\hline Treatment*Activated Carbon & 1 & 0.6366330 & 74.9891 & $<0.0001 *$ \\
\hline Time*Treatment*Activated Carbon & 1 & 0.1393236 & & $<$ \\
\hline
\end{tabular}


Table 3. Tukey's HSD Test for Presence of Activated Carbon and Treatment Type. The table refers to information in Figure 2 and Table 2. Tukey's HSD test is a post-hoc test for the ANCOVA which excludes the raw data from October 30th and treatments containing 50 mg/L of phosphorous. The Tukey's HSD test demonstrates a positive confidence quantile between samples with compared to without activated carbon, concluding there is significant difference between data sets. The $\alpha$-value of 0.05 was used to determine significant differences.

\section{For Activated Carbon}

\begin{tabular}{|c|c|c|}
\hline Measurement & Source & Value \\
\hline Confidence Quantile & & 1.96237 \\
\hline Ordered Differences Report (p-value) & $\mathrm{Y}$ and $\mathrm{N}$ activated carbon & 6.0835479 \\
\hline \multicolumn{3}{|l|}{ For Treatment Type } \\
\hline Measurement & Source & Tukey's HSD Value \\
\hline Confidence Quantile & & 1.96237 \\
\hline Ordered Differences Report (p-value) & $\begin{array}{l}\text { Treatment } 0 \mathrm{mg} / \mathrm{L} \text { by Treatment } 20 \mathrm{mg} / \mathrm{L} \\
\text { Treatment } 0 \mathrm{mg} / \mathrm{L} \text { by Treatment } 5 \mathrm{mg} / \mathrm{L} \\
\text { Treatment } 5 \mathrm{mg} / \mathrm{L} \text { by Treatment } 20 \mathrm{mg} / \mathrm{L}\end{array}$ & $\begin{array}{l}<0.0001 * \\
<0.0001 * \\
<0.0001 *\end{array}$ \\
\hline
\end{tabular}

Table 4. ANCOVA Summary Table of Nitrogen Readings Values, Excluding Those from October 30th and the $50 \mathrm{mg} / \mathrm{L}$ phosphorous-Containing Treatments. The table refers to information from Figure 3. The table demonstrates significance for variables (treatments, days, and activated carbon presence or absence) and their combinations. The "*" is used to represent interactions between the variables while "DF" denotes the degrees of freedom for each analysis of covariance. All data were significant $(p<0.05)$ except for the combined effects of "activated carbon*treatment type" and "time*activated carbon*treatment type."

\begin{tabular}{|l|c|c|c|c|}
\hline Source & DF & Sum of Squares & F Ratio & Prob > F \\
\hline Activated Carbon & 1 & 1558.8021 & 8.6539 & $<0.0040^{*}$ \\
\hline Treatment (mg/L) & 1 & 7957.1007 & 44.1751 & $<0.0001^{*}$ \\
\hline Time (Day) & 1 & 2880.0000 & 15.9888 & $0.0001^{*}$ \\
\hline Time*Activated Carbon & 1 & 845.0000 & 4.6911 & $<0.0324^{*}$ \\
\hline Treatment*Activated Carbon & 1 & 160.3706 & 0.8903 & $<0.3474$ \\
\hline Time*Treatment*Activated Carbon & 1 & 38.0453 & 0.2112 & $<0.6467$ \\
\hline
\end{tabular}


Table 5. ANCOVA Summary Table of Phosphorous Readings Values, Excluding Those from October 30th and the $50 \mathrm{mg} / \mathrm{L}$ phosphorous-Containing Treatments. The table refers to information from Figure 3. The table demonstrates significance for variables and their combinations. The "*" is used to represent interactions between the variables while "DF" denotes the degrees of freedom for each analysis of covariance. All data were significant $(p<0.05)$ except for the combined effects of "time*activated carbon" and "treatment type*activated carbon."

\begin{tabular}{|l|c|c|c|c|}
\hline Source & DF & \multicolumn{2}{c|}{ F Ratio } \\
\hline Activated Carbon & 1 & 0.00003063 & 8.1974 & $0.0050^{*}$ \\
\hline Treatment (mg/L) & 1 & 0.00077828 & 208.2977 & 105.4042 \\
\hline Time (Day) & 1 & 0.00039383 & 0.2710 & $0.0001^{*}$ \\
\hline Time*Activated Carbon & 1 & 0.00000101 & 23.6805 & 0.6037 \\
\hline Treatment*Activated Carbon & 1 & 0.00000582 & 4.1798 & $0.0433^{*}$ \\
\hline Time*Treatment*Activated Carbon & 1 & 0.00001562 & & 0.2144 \\
\hline
\end{tabular}


0 mg/L Treatment Type with Activated Carbon: Comparing Nitrogen Readings and Day

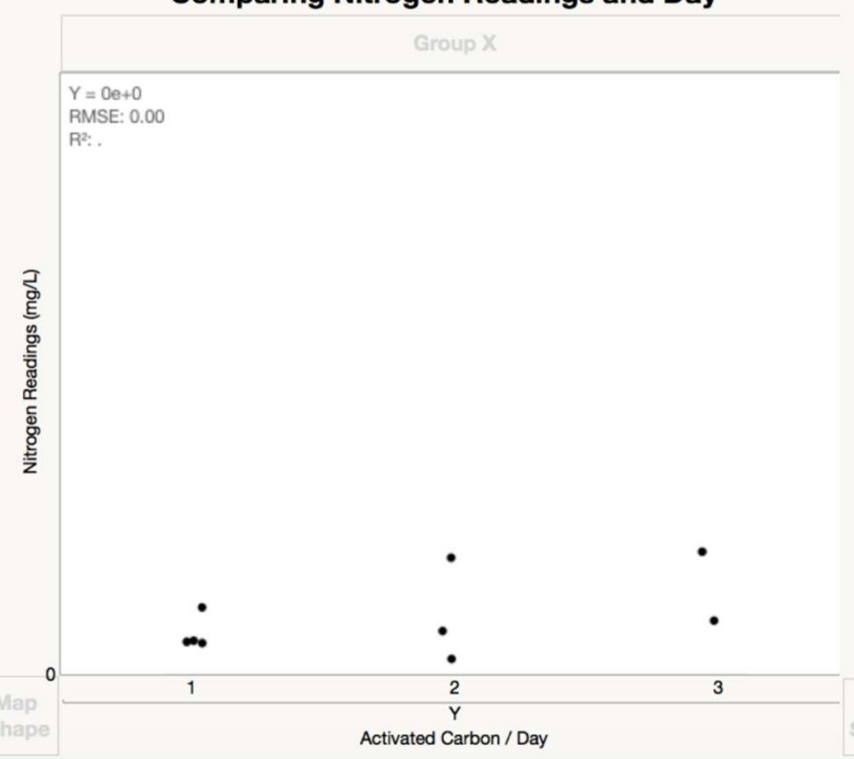

$5 \mathrm{mg} / \mathrm{L}$ Treatment Type with Activated Carbon: Comparing Nitrogen Readings and Day

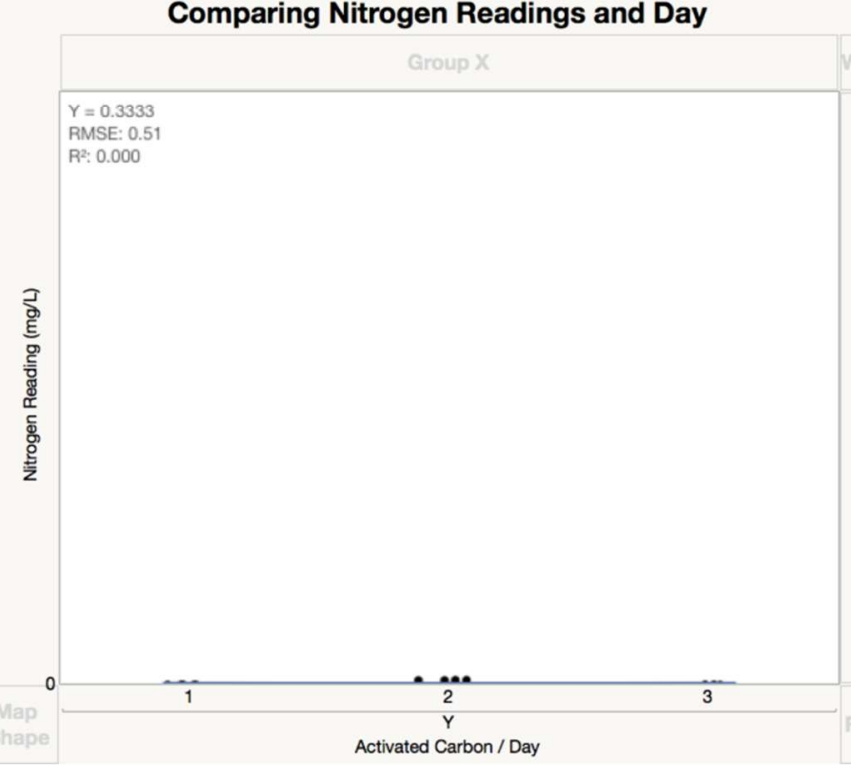

0 mg/L Treatment Type without Activated Carbon: Comparing Nitrogen Readings and Day

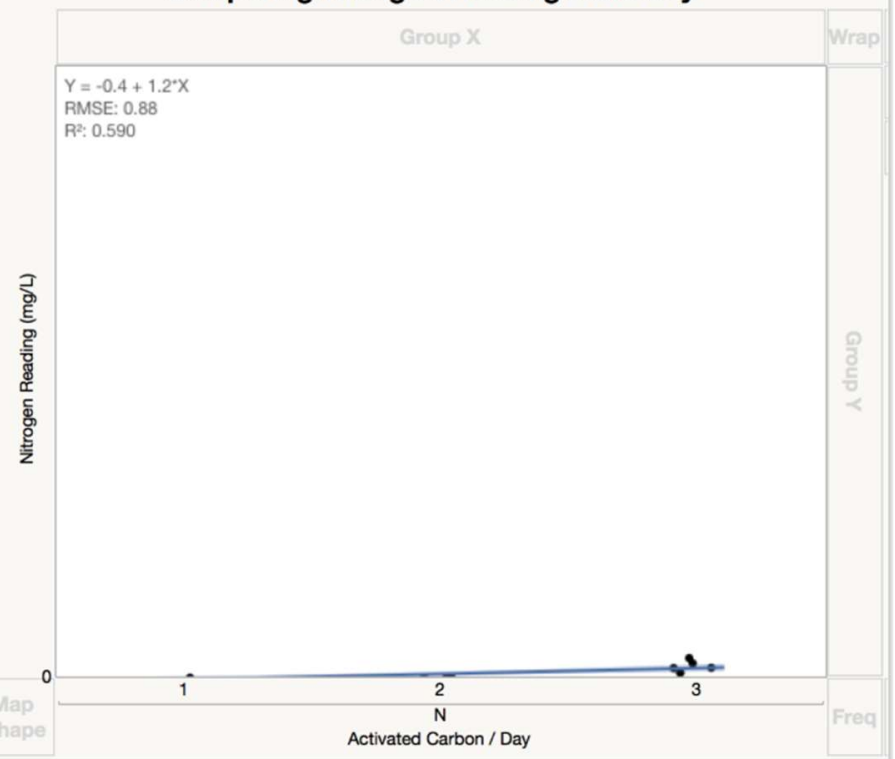

$5 \mathrm{mg} / \mathrm{L}$ Treatment Type without Activated Carbon: Comparing Nitrogen Readings and Day

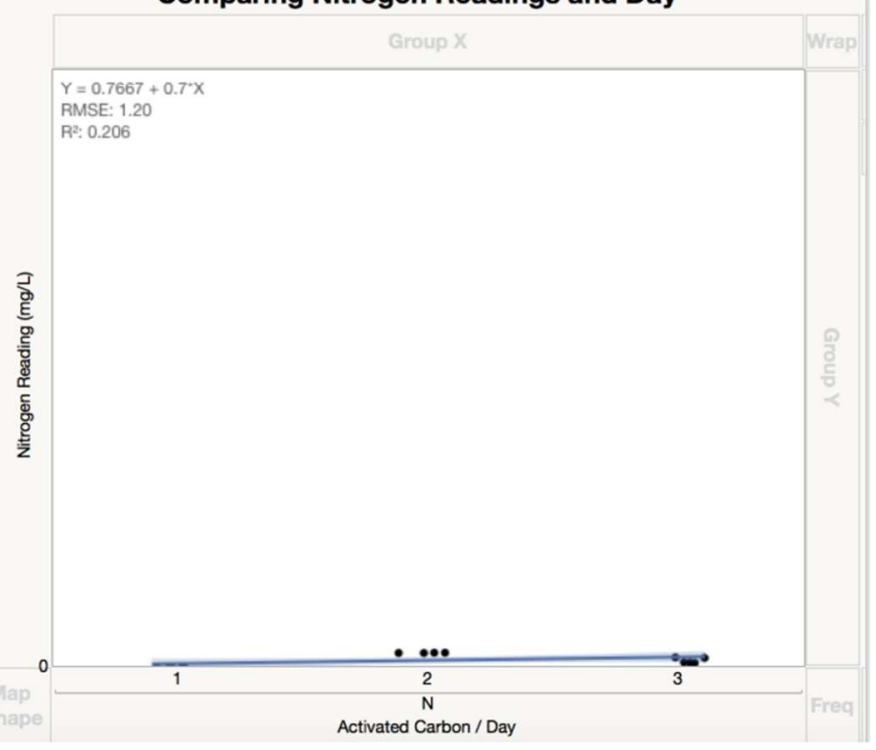




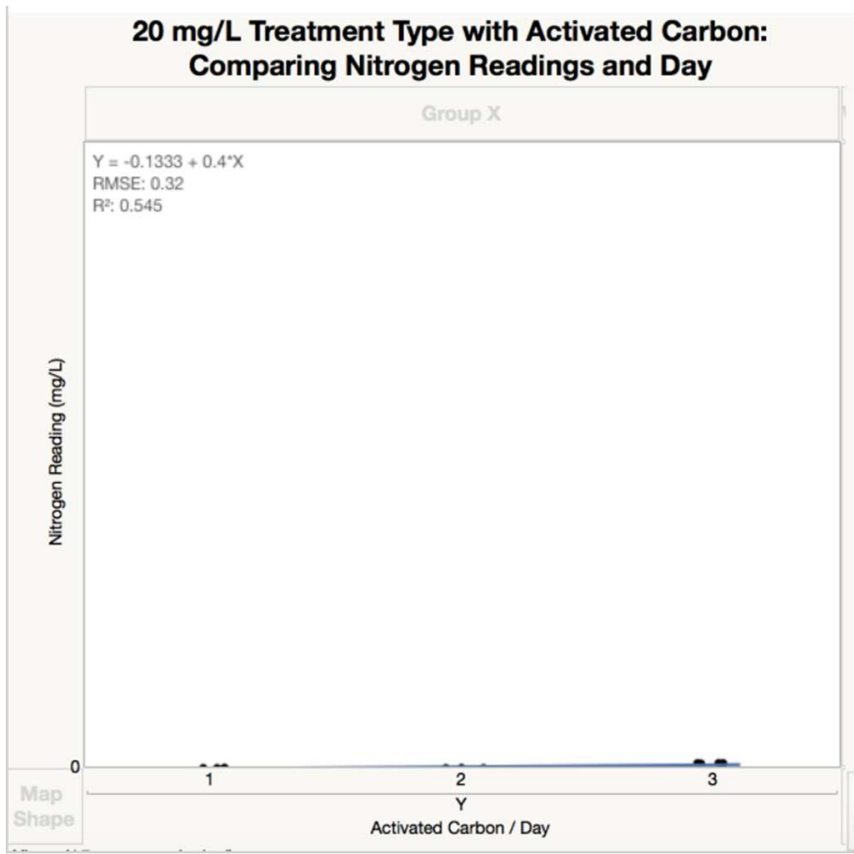

50 mg/L Treatment Type with Activated Carbon: Comparing Nitrogen Readings and Day

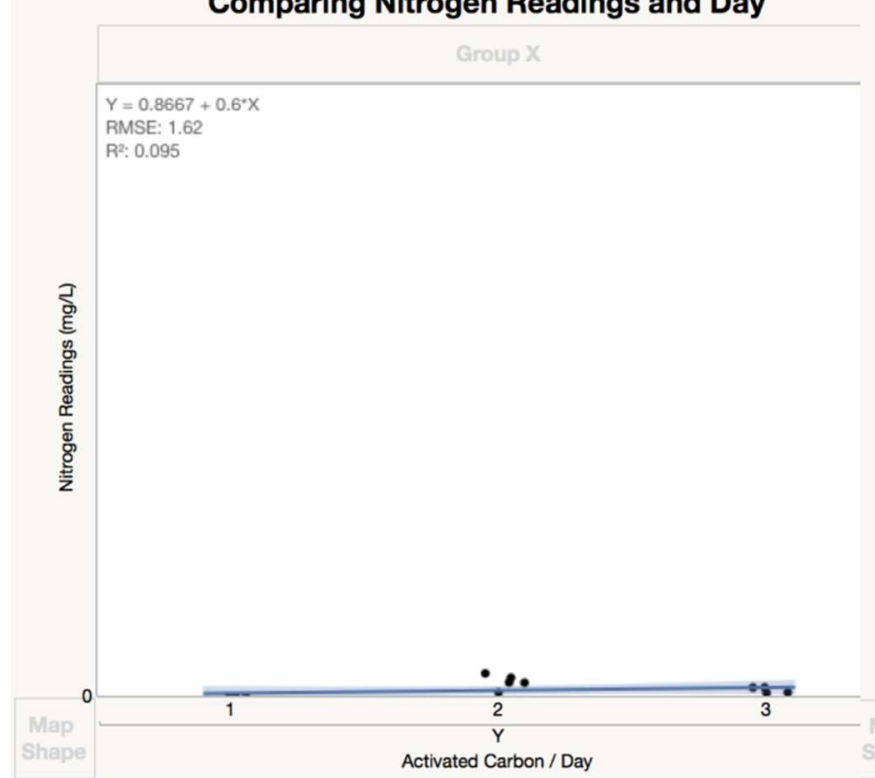

20 mg/L Treatment Type without Activated Carbon: Comparing Nitrogen Readings and Day

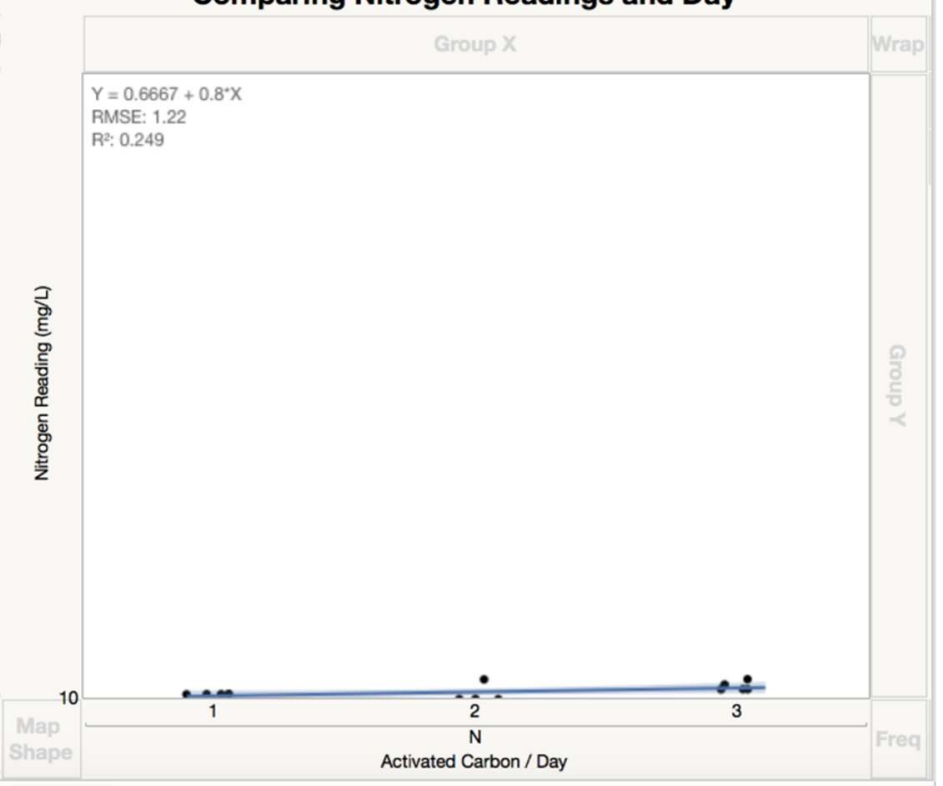

50 mg/L Treatment Type without Activated Carbon: Comparing Nitrogen Readings and Day

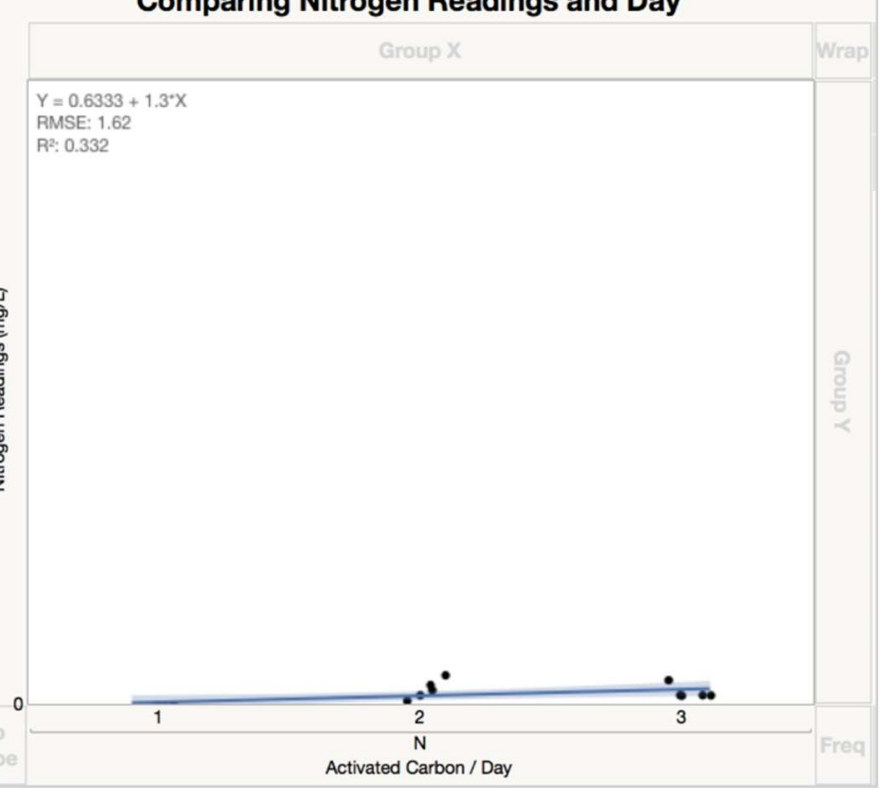

Figure 1. Scatterplots Based on Nitrogen Values for Treatment Types with and without Activated Carbon. Scatterplots graphing the nitrogen readings over time for both the presence and absence of activated carbon. API Aquarium nitrogen tests were used to quantify values of nitrogen in the solutions (Aquarium Pharmaceutical Incorporated: Nebraska, U.S). Lines of best fit traversing the data values provide an estimate of the change in nitrogen readings over the collection period. The figure refers to nitrogen data isolating treatment types, compared to Table 4 of the main text, which combines all treatment types with the analyses. 


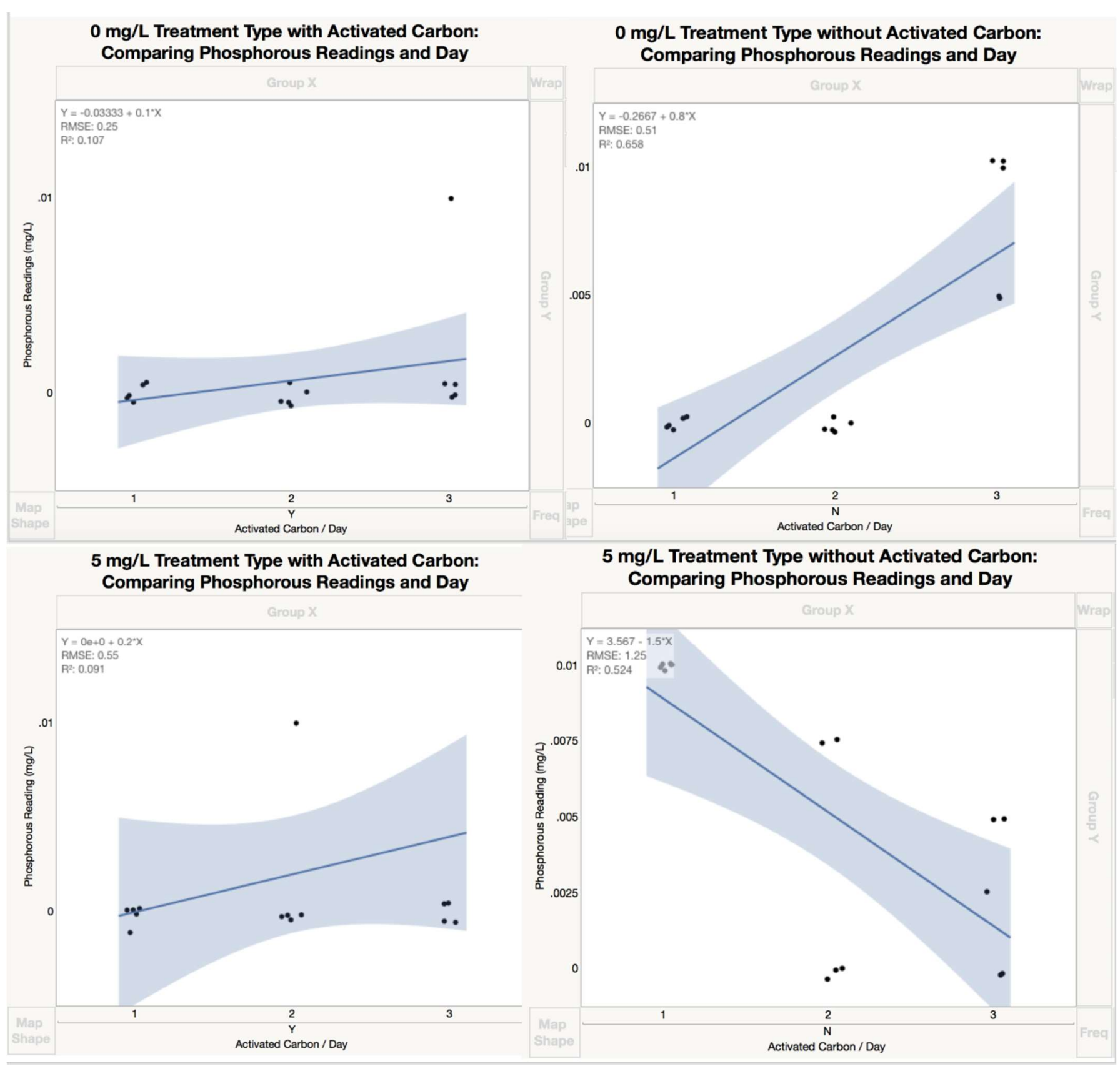




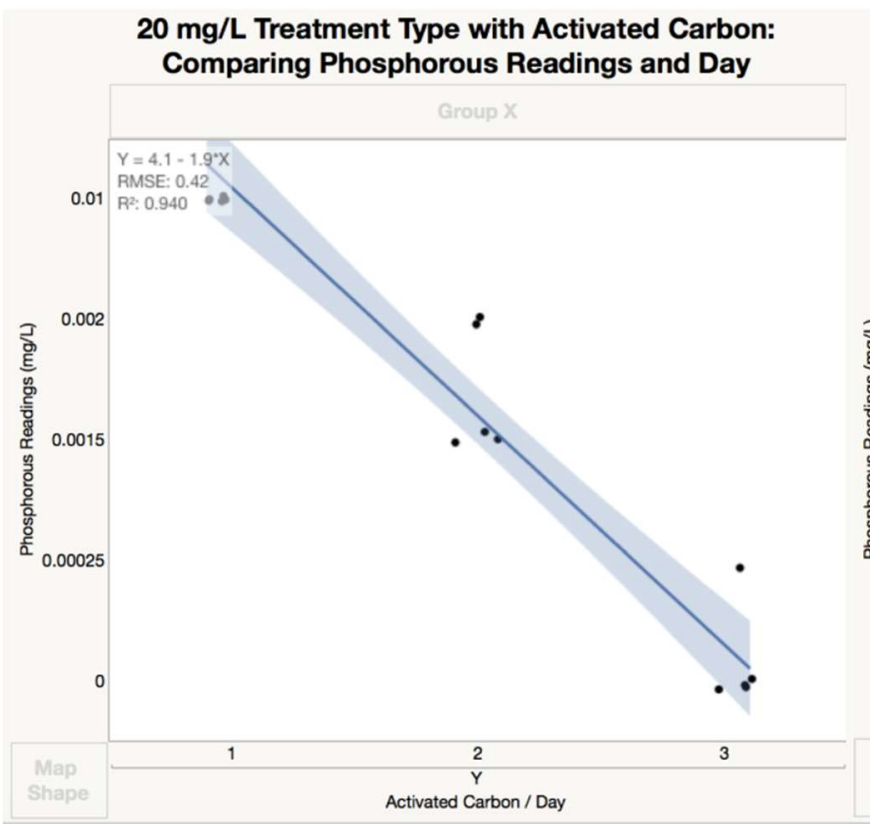

50 mg/L Treatment Type with Activated Carbon: Comparing Phosphorous Readings and Day

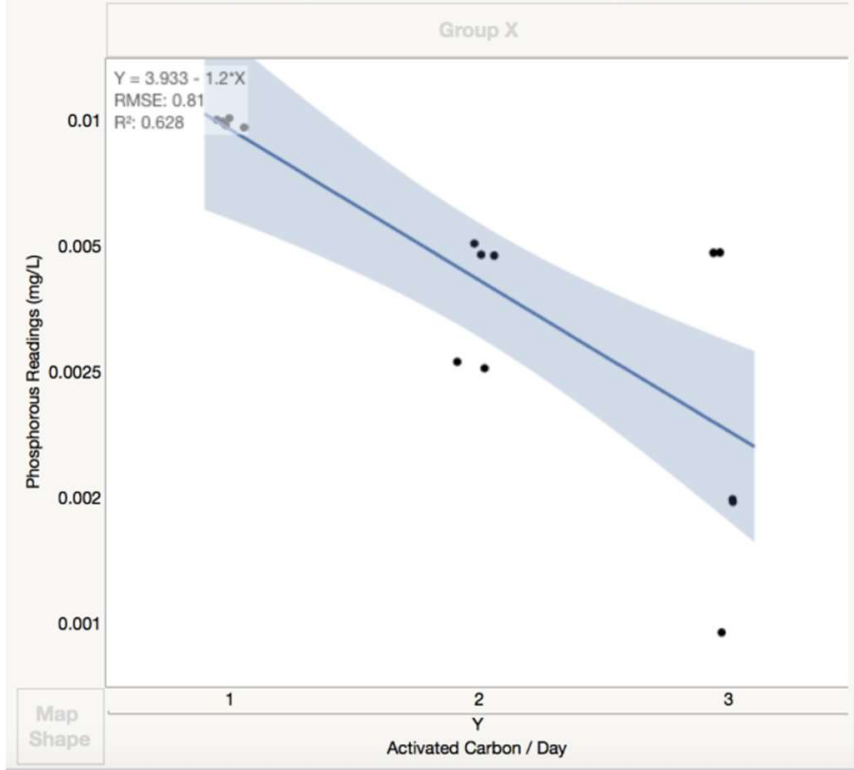

$20 \mathrm{mg} / \mathrm{L}$ Treatment Type without Activated Carbon: Comparing Phosphorous Readings and Day

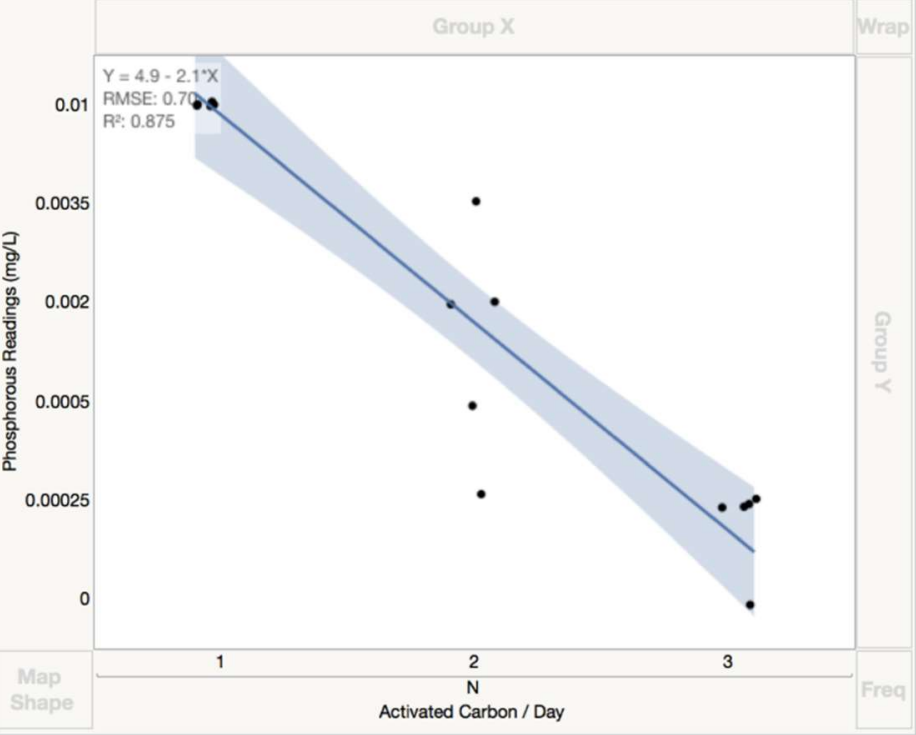

50 mg/L Treatment Type without Activated Carbon: Comparing Phosphorous Readings and Day

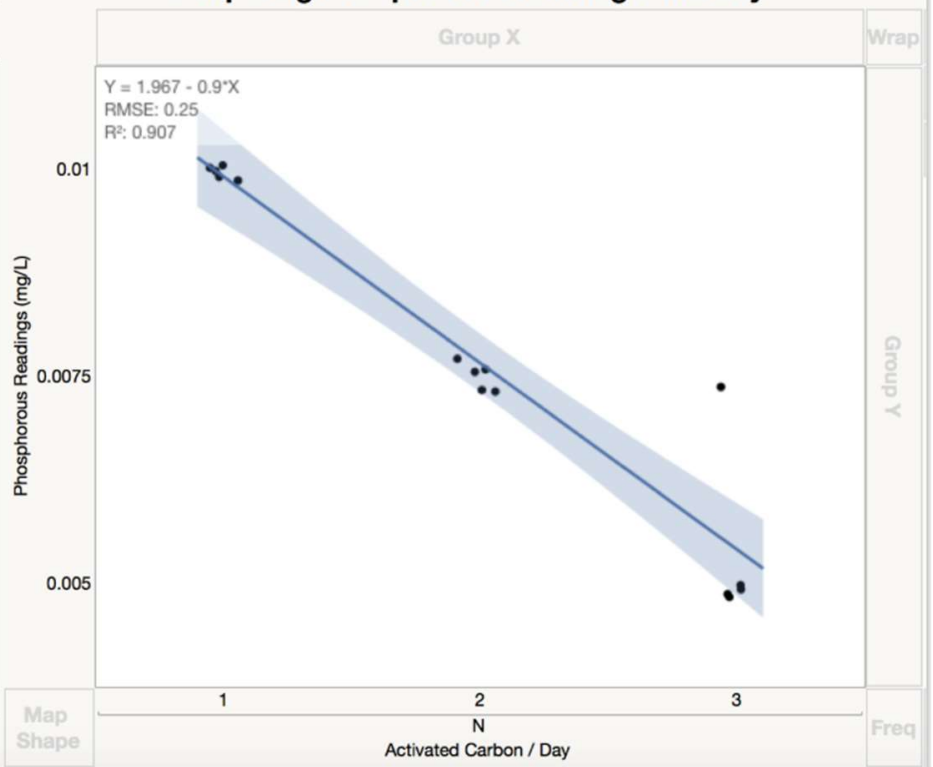

Figure 2. Scatterplots Based on Phosphorous Values for Treatment Types with and without Activated Carbon. Scatterplots graphing phosphorous readings over time for both the presence and absence of activated carbon. API Aquarium phosphorus tests were used to quantify values of this element in the solutions (Aquarium Pharmaceutical Incorporated: Nebraska, U.S). Lines of best fit traversing the data values provide an estimate of the change in phosphorous readings over the collection period. The figure refers to phosphorous data isolating treatment types, compared to Table5 of the main text, which combine all treatment types within the analyses. 
Table 1. ANCOVA of Initial Raw Data Values. The table outlines significance of variables and interactions between them on the fluorescence readings. The analysis includes all raw data, including those from October 30th and the $50 \mathrm{mg} / \mathrm{L}$ phosphorous treatment which were excluded in other analyses of covariance. The "*" is used to represent interactions between the variables while "DF" denotes the degrees of freedom for each analysis of covariance. The "time*biochar" analysis demonstrates less significance, likely due to the error from the October 30th data.

\begin{tabular}{|l|c|c|c|c|}
\hline Source & DF & Sum of Squares & \multicolumn{2}{c|}{ F Ratio } \\
\hline Activated Carbon & 1 & 0.4574166 & 81.9863 & $<0.0001 *$ \\
\hline Treatment (mg/L) & 1 & 5.5238264 & 330.0260 & 309.9657 \\
\hline Time (Day) & 1 & 1.7293554 & 7.0419 & $0.0001 *$ \\
\hline Time*Activated Carbon & 1 & 0.0392870 & 54.3902 & $<0.0001 *$ \\
\hline Treatment*Activated Carbon & 1 & 0.9103578 & 9.7909 & $<0.0001 *$ \\
\hline Time*Treatment*Activated Carbon & 1 & 0.1638753 & \\
\hline
\end{tabular}

Table 2. Meta-Analysis Raw Data. A raw data table of the information used in the meta-analysis of studies researching phosphorous sorption by biochar or activated carbon in aqueous solutions. The effect size was found from these studies as the phosphorous sorption ( $\left.\mathrm{mg} \cdot \mathrm{kg}^{-1}\right)$ over time (days).

\begin{tabular}{|c|c|c|c|c|c|c|}
\hline \multicolumn{1}{|c|}{ Study } & Study \# & Environment & \multicolumn{1}{c|}{ Sample Size } & Effect Size & Direction of Effect & Study Size \\
\hline Dalahmeh & 6 & Aqueous & 2 & 0.0338 & neutral & 0.0676 \\
\hline Fang et al. & 7 & Aqueous & 9 & 15.14 & positive & 136.26 \\
\hline Fang et al. & 7 & Aqueous & 9 & 15.24 & positive & 137.16 \\
\hline Fang et al. & 7 & Aqueous & 9 & 15.48 & positive & 139.32 \\
\hline Fang et al. & 7 & Aqueous & 9 & 15.98 & positive & 143.82 \\
\hline Fang et al. & 7 & Aqueous & 9 & 16.08 & positive & 144.72 \\
\hline Fang et al. & 7 & Aqueous & 9 & 16.5 & positive & 148.5 \\
\hline
\end{tabular}


Table 3. Meta-Analysis Raw Data. A raw data table of the information used in the meta-analysis of studies researching phosphorous sorption by biochar or activated carbon in both aqueous solutions and soil mixtures. The effect size was found from these studies as the phosphorous adsorption $\left(\mathrm{mg} \cdot \mathrm{kg}^{-1}\right)$ over the equilibrium solution $\left(\mathrm{mg} \cdot \mathrm{L}^{-1}\right)$.

\begin{tabular}{|c|c|c|c|c|c|c|}
\hline Study & Study \# & Environment & Sample Size & Effect Size & Direction of Effect & Study Size \\
\hline Morales et al. & 1 & Soil & 4 & 51.43 & positive & 205.72 \\
\hline Morales et al. & 1 & Soil & 4 & 14.26 & positive & 57.04 \\
\hline Morales et al. & 1 & Soil & 4 & 1.13 & positive & 4.52 \\
\hline Morales et al. & 1 & Soil & 4 & 10.55 & positive & 42.2 \\
\hline Morales et al. & 1 & Soil & 4 & 10.37 & positive & 41.48 \\
\hline Morales et al. & 1 & Soil & 4 & 1 & positive & 4 \\
\hline Morales et al. & 1 & Soil & 4 & 19.88 & positive & 79.52 \\
\hline Morales et al. & 1 & Soil & 4 & 19.82 & positive & 79.28 \\
\hline Morales et al. & 1 & Soil & 4 & 2.07 & positive & 8.28 \\
\hline Morales et al. & 1 & Soil & 12 & 12.12 & positive & 145.44 \\
\hline $\mathrm{Xu}$ et al. & 2 & Soil & 8 & 16.575 & positive & 132.6 \\
\hline Xu et al. & 2 & Soil & 8 & 30.5 & positive & 244 \\
\hline $\mathrm{Xu}$ et al. & 2 & Soil & 8 & 86.675 & positive & 693.4 \\
\hline Chintala et al. & 3 & Soil & 7 & 100 & positive & 700 \\
\hline Chintala et al. & 3 & Soil & 7 & 14.4 & positive & 100.8 \\
\hline Chintala et al. & 3 & Soil & 7 & 86.36 & positive & 604.52 \\
\hline Soinne et al. & 4 & Soil & 5 & 0.903 & neutral & 4.514 \\
\hline Soinne et al. & 4 & Soil & 5 & 1.239 & neutral & 6.196 \\
\hline Soinne et al. & 4 & Soil & 5 & 0.844 & neutral & 4.219 \\
\hline Chen et al. & 5 & Aqueous & 14 & 1.28 & positive & 17.92 \\
\hline Chen et al. & 5 & Aqueous & 14 & 1.60 & positive & 2240 \\
\hline Chen et al. & 5 & Aqueous & 14 & 224 & positive & 3136 \\
\hline Chen et al. & 5 & Aqueous & 14 & 8.37 & positive & 117.18 \\
\hline Chen et al. & 5 & Aqueous & 14 & 460 & positive & 6440 \\
\hline
\end{tabular}

